\title{
Towards the detection of static ATP levels above primary PTPRろ-osteoblastic cells and their knock-out mutants by ATP microbiosensors
}

\author{
Charlotte Steinbach ${ }^{1}$, Elena Hecht ${ }^{1}$, Sonja Dobler ${ }^{2}$, Astrid Liedert' ${ }^{2}$, Anita Ignatius ${ }^{2}$, Boris Mizaikoff ${ }^{1}$, \\ Christine Kranz ${ }^{1}$ \\ ${ }^{1}$ Institute of Analytical and Bioanalytical Chemistry, University of Ulm, Albert-Einstein-Allee 11, 89081, \\ Germany, \\ charlotte.steinbach@uni-ulm.de \\ ${ }^{2}$ Institute of Orthopaedic Research and Biomechanics, University of Ulm, Helmholtzstraße 14, 89081, \\ Germany
}

\begin{abstract}
:
Adenosine-5 ${ }^{`}$-triphosphate (ATP) holds a significant role as omnipresent energy source and as autocrine and paracrine signaling molecule in many cells such as lung cells and bone cells [1]. ATP is considered to be involved in the mechanical stress response of bone cells such as bone-resorbing osteoblast cells or receptor-proteine-tyrosine-phosphatase-zeta (PTPRל) - osteoblastic cells [2], which are involved in bone formation, bone regeneration and the control of bone volume. ATP release stimulates the proliferation of these P2 - receptor cell types [3,4]. The "deficient" knock-out mutant behaves different in proliferation and differentiation and thus the ATP release above these cells is expected to be altered. A localized detection of ATP at the cellular level is therefore of significant importance. Using amperometric ATP microbiosensors with diameters ranging from $10-50 \mu \mathrm{m}$ enables localized ATP measurements above wild type and knock-out cells.
\end{abstract}

Key words: ATP, localized determination, biosensor, osteoblastic cells, static conditions.

\begin{abstract}
ATP Microbiosensors
In the present study microelectrodes with diameters of 10 and $50 \mu \mathrm{m}$ are used as transducer for ATP biosensors. This biosensors base on a competitive assay with glucose converting oxidoreductases (e.g. GOD or PQQGDH) and hexokinase (HEX) immobilized at the surface of the microelectrode $(5,6)$. The calibration and characterization of ATP biosensors (a micrograph of such an ATP microbiosensors is shown in figure 1) was performed prior to localized ATP measurements. Calibration was obtained in buffer solution by adding first an aliquot of 300 $\mu \mathrm{l} 0.2 \mathrm{M}$ glucose solution and successive aliquots of $1 \mathrm{mmol}$ ATP solution; a representative calibration curve is shown in figure 2 .
\end{abstract}

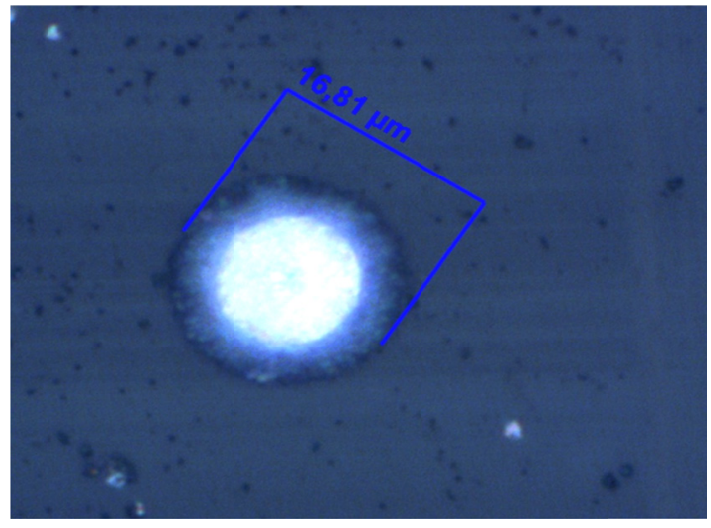

Fig. 1. Micrograph of an immobilized layer at an UME of $10 \mu \mathrm{m}$ diameter 


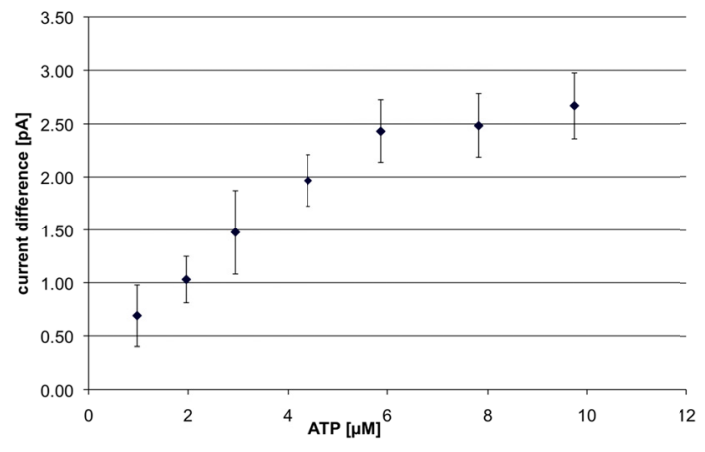

Fig. 2. Exemplary calibration curve of an ATP biosensor (transducer: $10 \mu m$ UME); different aliquots of ATP stock solution (1 mmol) were added to a $0.2 \mathrm{M}$ glucose solution while amperometric measurements at $0.6 \mathrm{~V}$ vs. $\mathrm{Ag} / \mathrm{AgCl}$ reference were performed.

\section{Experimental section}

The experimental set-up for the detection of ATP release under static conditions is shown in Fig. 3. Experiments were conducted in a threeelectrode setup in combination with a scanning electrochemical microscope for positioning the biosensor close to the cell surface. A dual microelectrode assembly served as working electrodes (WEs), using one electrode for positioning and the second as transducer for the microbiosensor. For positioning of the ATP biosensor, double-electrode assembly was used, where one electrode serves as ATP biosensor and the other remains unmodified for recording current-distance curves using a scanning electrochemical microscopy (SECM) set-up. The current obtained from oxygen reduction at $-600 \mathrm{mV}$ vs. $\mathrm{Ag} / \mathrm{AgCl}$ is recorded in buffered solution $(\mathrm{pH}=7.4)$ while the electrode assembly is approached to the surface (green arrow in figure 4). The approach was stopped at a distance of approx. $10 \mu \mathrm{m}$.

\section{References}

[1] N.R. Jorgensen, S.T. Geist, R. Civitelli, T.H. Steinberg, ATP- and gap junction-dependent intercellular calcium signaling in osteoblastic cells, J Cell Biol. 139(2), 497-506 (1997); doi: 0021-9525/97/10/497/10

[2] K.A. Buckley, S.L. Golding, J.M. Rice, J.P. Dillon, J.A. Gallagher, Release and interconversion of P2 receptor agonists by human osteoblast-like cells, The FASEB Journal 17, 1401-1410 (2003); doi: 10.1096/fj.02-0940com

[3] T. Schinke, M. Gebauer, A.F. Schilling, S. Lamprianou, M. Priemel, C. Mueldner, C. Neunaber, T. Streichert, A. Ignatius, S. Harroch, M. Amling, The protein tyrosine phosphatase Rptp $\zeta$ is expresses in differentiated osteoblasts and affects bone formation in mice, Bone 42, 524-534 (2008); doi: 10.1016/j.bone.2007.11.009
Then the ATP biosensor is biased at $600 \mathrm{mV}$ and moved towards the cell monolayers.

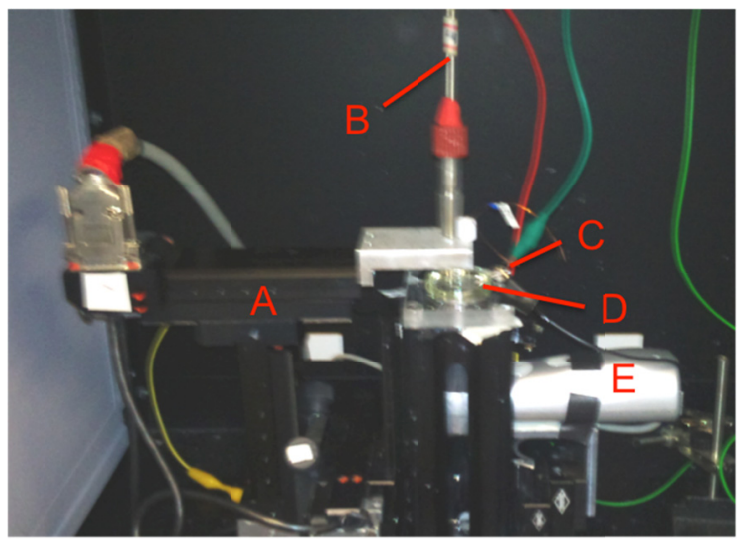

Fig. 3. Set up used for measurements of ATP release from osteoblastic cells under static conditions. $A$ is the stage, adjustable in three axes, $B$ the platinum counter electrode, $C$ is the working electrode, $D$ is the ibidi-dish with the cultivated cells and $E$ is the video microscope.

The cultivation of both cell typs were carried out using a double-chamber insert as shown in figure 4. After cell seeding and cultivation, the insert was removed and the whole dish is filled with buffer (ringers solution) for localized ATP detection.

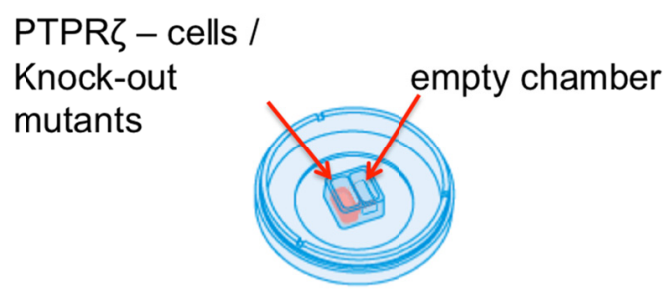

Fig. 3. Ibidi cultivation dish with insert, one cell type (either PtPRS or K.O-mutants) was seeded in the insert, the other chamber was left empty.

[4] J.A. Gallagher, ATP P2 receptors and regulation of bone effector cells, J Musculoskel Neuron Interact, 4(2), 125-127 (2004); PubMed: 15615109

[5] A. Kueng, C. Kranz, B. Mizaikoff, Imaging of ATP membrane transport with dual micro-disk electrodes and scanning electrochemical microscopy, Biosensors and Bioelectronics, 21, 346-353 (2005); doi: 10.1016/j.bios.2004.10.020

[6] J-F. Masson, C. Kranz, B. Mizaikoff, E. B. Gauda, Amperometric ATP Microbiosensors for the Analysis of Chemosensitivity at Rat Carotid Bodies, Anal. Chem. 80, 3991-3998 (2008); doi: 10.1021/ac7018969

[7] C. Weber, E. Gauda, B. Mizaikoff, C. Kranz, Developmental aspects of amperometric ATP biosensors based in entrapped enzymes, Anal Bioanal Chem. 395, 1729-1735 (2009); doi: 10.1007/s00216-009-3125-x 